\title{
Combined rigid videolaryngoscopy-flexible bronchoscopy for intubation
}

\author{
Sylvain Boet ${ }^{1}$, M. Dylan Bould ${ }^{2}$, and Pierre A. Diemunsch ${ }^{3}$ \\ ${ }^{1}$ Department of Anesthesiology, St. Michael's Hospital, University of Toronto, Toronto, ${ }^{2}$ Department of Anesthesiology, The Children's \\ Hospital of Eastern Ontario, University of Ottawa, Ottawa, Canada, ${ }^{3}$ Department of Anesthesiology and Critical Care, Hopital de \\ Hautepierre, University of Strasbourg, Avenue Moliere, France
}

\section{To the Editor}

We read with interest the article by Choi et al. [1] in which the authors report a case of a airway management with combined use of glidescope ${ }^{\circledR}$ videolaryngoscope and fiberoptic bronchoscope in a patient with a supraglottic mass. This case report addresses the important clinical concept of the combined use of flexible bronchoscopy with rigid videolaryngoscopy to benefit from the strengths of both techniques. The videolaryngoscope allows vision of the position of the tip of the bronchoscope and facilitates progression of the bronchoscope towards the larynx by keeping the oropharynx open and reducing erratic lateral advancement.

We would like to congratulate Choi et al. for adding to the largest previously published case series describing this multimodal airway approach. Sixteen patients without predicted abnormal airway were successfully intubated on the first attempt with the combined use of a videolaryngoscope (DCI, Karl Storz, Tuttlingen, Germany) and of a flexible bronchoscope [2]. The association of a videolaryngoscope and a flexible bronchoscope has to be considered as a concept that is independent of the specific brand or type of videolaryngoscope and flexible bronchoscope. Choi et al. confirmed the potential utility of this technique for the management of both normal and difficult airways.

\section{References}

1. Choi GS, Park SI, Lee EH, Yoon SH. Awake Glidescope(R) intubation in a patient with a huge and fixed supraglottic mass -A case report. Korean J Anesthesiol 2010; 59: S26-9.

2. Greib N, Stojeba N, Dow WA, Henderson J, Diemunsch PA. A combined rigid videolaryngoscopy-flexible fibrescopy intubation technique under general anesthesia. Can J Anaesth 2007; 54: 492-3.

\section{Author's Reply}

We would like to thank Dr. Boet in his interest and valuable opinion on our manuscript. We were also impressed with Dr. Greib's publication [1] and thought that it was a meaningful attempt in managing difficult airways.

Due to the recent development of technology, the diameter of the Fiberoptic bronchoscopy (FOB) has decreased but as a result its view has become that much narrower. Therefore, in such cases were anatomical abnormalities lies within the airway, we find it difficult to accurate the proceeding direction of the fiber and its location. Also, the Glidescope Videolaryngoscope (GVL) may provoke palate perforation [2] or injury to the arytenoid cartilage due to multiple attempts. Even a 3.7\% failure rate in intubation has been reported [3].

Therefore, we hope that a new airway management product which compromises the pros and cons of the GVL and FOB mat be developed in the future.

\section{References}

1. Greib N, Stojeba N, Dow WA, Henderson J, Diemunsch PA. A combined rigid videolaryngoscopy-flexible fibrescopy intubation technique under general anesthesia. Can J Anaesth 2007; 54: 492-3.

Corresponding author: Sylvain Boet, M.D., MEd., Department of Anesthesiology, St. Michael's Hospital, University of Toronto, 30 Bond Street, Toronto, Ontario, M5B 1W8, Canada. Tel: 1-4168646060, Fax: 1-4168646014, E-mail: Boets@smh.ca

(c) This is an open-access article distributed under the terms of the Creative Commons Attribution Non-Commercial License (http:// creativecommons.org/licenses/by-nc/3.0/), which permits unrestricted non-commercial use, distribution, and reproduction in any medium, provided the original work is properly cited. 
2. Cooper RM. Complications associated with the use of the GlideScope videolaryngoscope. Can J Anaesth 2007; 54: 54-7.

3. Cooper R, Pacey J, Bishop M, McCluskey S. Early clinical experience with a new videolaryngoscope (GlideScope) in 728 patients. Can J Anaesth 2005; 52: 191-8. 